Info Artikel Diterima Januari 2021

Disetujui Maret 2021

Dipublikasikan April 2021

\title{
PENGARUH PERLAKUAN SUHU DAN BEBERAPA GENOTIPE TERHADAP VIABILITAS DAN VIGOR BENIH KUBIS BUNGA (Brassica Oleracea Var. Botrytis L.) PADA DATARAN RENDAH
}

\section{THE EFFECT OF TEMPERATURE TREATMENT AND SEVERAL GENOTYPES ON VIABILITY AND VIGOUR OF CAULIFLOWER SEEDS (Brassica Oleraceavar. Botrytis L.) IN LOWLANDS}

\author{
Lestari, Elia Azizah, Winda Rianti, Sugiarto \\ Program Studi Agroteknologi \\ Fakultas Pertanian Universitas Singaperbangsa Karawang
}

Email: maulanalestari54@gmail.com

\begin{abstract}
The aim of this study was to obtain the best temperature on several genotypes so as to increase the best viability and vigour of cauliflower seeds in the lowlands. The research was conducted at the Laboratory Agronomy Faculty of Agriculture, Singaperbangsa University Karawang. The research method used was an experimental method with a two-factor completely randomized design (CRD). The first factor is temperature which consists of room temperature without air conditioning (P0), air-conditioned room temperature (P1) and refrigerator temperature (P2). The second factor is genotypes consisting of Viola (B1), Tegar 45 (B2), Snow Waltz (B3), Jayanti (B4), Giga (B5), Snow White (B6), Diamond (B7), Orient (B8), Roo So 45 (B9), Forum (B10), Bima (B11), F1 Hybrid (B12) and Arjuna (B13). Each treatment was repeated 2 times so that 78 experiments were obtained. The results of the post-storage experiment, there were an interaction with the parameters of germination, concurrency of growth and vigor index. The best treatment was room temperature without AC genotype Roo So 45 (P0B9).
\end{abstract}

Keywords: Cauliflower, genotype, temperature, viability, vigour.

\begin{abstract}
ABSTRAK
Penelitian ini bertujuan untuk mendapatkan suhu terbaik pada beberapa genotipe sehingga dapat meningkatkan viabilitas dan vigor benih kubis bunga yang terbaik pada dataran rendah. Penelitian dilakukan di Laboratorium Agronomi Fakultas Pertanian Universitas Singaperbangsa Karawang. Metode penelitian yang digunakan yaitu metode eksperimental dengan Rancangan Acak Lengkap (RAL) dua faktor. Faktor pertama yaitu Suhu yang terdiri dari suhu ruang tanpa AC (P0), suhu ruang ber-AC (P1) dan suhu kulkas (P2). Faktor kedua yaitu beberapa genotipe yang terdiri dari Viola (B1), Tegar 45 (B2), Snow Waltz (B3), Jayanti (B4), Giga (B5), Snow White (B6), Diamond (B7), Orient (B8), Roo So 45 (B9), Forum (B10), Bima (B11), F1 Hybrid (B12) dan Arjuna (B13). Setiap perlakuan diulang 2 kali sehingga diperoleh 78 percobaan. Hasil experiment
\end{abstract}


setelah proses penyimpanan 2 bulan simpan terdapat interaksi perlakuan suhu dan beberapa genotipe terhadap parameter daya berkecambah, keserempakan tumbuh dan indeks vigor. Perlakuan terbaik adalah suhu ruang tanpa AC dan genotipe Roo So $45\left(\mathrm{P}_{0} \mathrm{~B}_{9}\right)$.

Kata kunci: Kubis bunga, suhu, genotipe, viabilitas, vigor.

\section{PENDAHULUAN}

Kubis bunga merupakan salah satu jenis sayuran populer karena mempunyai peran penting untuk kesehatan. Menurut Marliah, et.al. (2013) didalam kubis bunga mempunyai kandungan yang sangat dibutuhkan dalam tubuh, salah satunya mineral dan vitamin dan hal tersebut menjadikan kubis bunga sebagai salah satu sayuran yang permintaannya terus meningkat. Dan komposisi zat gizi dan mineral setiap $100 \mathrm{~g}$ kubis adalah kalori $(25,0 \mathrm{kal})$, protein $(2,4 \mathrm{~g})$, karbohidrat (4,9 g), kalsium $(22,0 \mathrm{mg})$, fosfor $(72,0 \mathrm{mg})$, zat besi $(1,1 \mathrm{mg})$, vitamin A (90,0 mg), vitamin B1 (0,1 mg), vitamin C (69,0 mg), dan air $(91,7 \mathrm{~g})$.

Salah satu faktor utama yang menentukan keberhasilan peningkatan produksi dalam budidaya kubis bunga adalah benih. Peningkatan produksi banyak ditunjang oleh benih bermutu atau benih bersertifikat (Hutabarat, et.al, 2013). Viabilitas benih dipakai untuk mengetahui kemampuan tumbuh normal dalam kondisi optimal dan sub optimal (Subantoro dan Prabowo, 2013). Penggunaan benih bermutu berasal dari benih yang bervarietas unggul sehingga mampu mengurangi risiko kegagalan budidaya. Selain itu benih bermutu bebas dari serangan hama dan penyakit, sehingga produktivitas akan meningkat (Sari dan Faisal, 2017). Viabilitas benih dapat dilihat dari persentase daya berkecambah benih, kecepatan perkecambahan dan vigor akhir dari kecambah. Setiap varietas memiliki daya berkecambah yang berbeda-beda, disebabkan karena setiap benih mempunyai ukuran, kandungan zat makanan, ketebalan kulit dan umur panen yang berbeda (Oktaviana, et.al, 2016).

Perbedaan sifat genotipe yang baik maupun kurang baik disebabkan oleh faktor genetik dari setiap benih dan lingkungannya. Genotipe yang baik akan menghasilkan produksi tinggi, tahan terhadap hama dan penyakit, responsif terhadap kondisi pertumbuhan yang lebih baik (Sari dan Faisal, 2017). Sementara faktor lingkungan merupakan faktor yang tidak mudah untuk dikendalikan karena faktor ini melibatkan kondisi eksternal, seperti kondisi penyimpanan benih. Mufid (2017) menyatakan bahwa viabilitas benih mengalami penurunan akibat serangga, jamur atau kerusakan alami selama penyimpanan berlangsung. Sementara hal yang mempengaruhi lingkungan penyimpanan yaitu tingkat kelembaban relatif udara dan suhu lingkungan.

Menurut Saputri, et.al., (2020) benih kubis bunga umur simpannya lebih rendah, karena itu suhu dan kelembaban lingkungan simpan harus diatur sesuai dengan kebutuhan. Hal ini akan berpengaruh terhadap kerusakan benih dan penurunan laju perkecambahan akibat penurunan viabilitas. Pada suhu $4^{0} \mathrm{C}$ (kulkas) memberikan persentase daya berkecambah pada kubis paling tinggi (Panggabean dan Haris (1994) dalam Sugiarto, et.al. 2018). Perlakuan suhu ruang tanpa $\mathrm{AC}\left( \pm 25^{\circ} \mathrm{C}\right)$ pada benih kenanga menunjukkan rata-rata harian mampu 
mempertahankan viabilitasnya dengan persentase perkecambahan cukup baik pada semua media penyimpanan (Nurhayani dan Wulandari, 2019). Adapun perlakuan suhu ruang ber-AC $\left(17-19^{\circ} \mathrm{C}\right)$ pada benih kedelai memiliki daya kecambahnya lebih dari $80 \%$, atau masih memenuhi standar mutu benih yang baik dan bisa digunakan sebagai bahan tanam (Purwanti, 2015). Penelitian ini bertujuan untuk mendapatkan suhu terbaik pada beberapa varietas sehingga dapat meningkatkan viabilitas dan vigor benih kubis bunga yang terbaik pada dataran rendah.

\section{BAHAN DAN METODE}

Penelitian dilaksanakan di Laboratorium Agronomi, OPT, Bioteknologi Tanah Fakultas Pertanian Universitas Singaperbangsa Karawang. Penelitian dilakukan selama 3 bulan. Waktu penelitian dimulai dari Bulan Agustus sampai dengan Bulan November 2020.Alat yang digunakan pada penelitian ini meliputi bak perkecambahan, alat pengecambah benih (germinator), desikator, baki, sarung tangan, pinset, penggaris, timbangan analitik, amplop, dan kulkas. Bahan yang digunakan meliputi benih kubis bunga, aquadest, plastik, kertas merang, label, tisu dan selotip.

Metode yang digunakan dalam penelitian ini metode eksperimen dengan menggunakan Rancangan Acak Lengkap (RAL) faktorial, yaitu dengan 2 faktor dan perlakuan tersebut diulang sebanyak 2 kali sehingga didapatkan 78 unit. Faktor 1 yaitu suhu dan faktor 2 yaitu beberapa genotipe. Faktor suhu terdiri atas 3 taraf yaitu $\mathrm{P} 0=$ suhu ruang tanpa $\mathrm{AC}\left(26,2^{0} \mathrm{C}-29^{0} \mathrm{C}\right), \mathrm{P} 1=$ suhu ruang ber-AC $\left(20^{\circ} \mathrm{C}-26,7^{\circ} \mathrm{C}\right)$ dan $\mathrm{P} 2=$ suhu kulkas $\left(1,5^{\circ} \mathrm{C}-6,2^{\circ} \mathrm{C}\right)$, sementara faktor beberapa genotipe terdiri atas 13 taraf yaitu $\mathrm{B} 1=$ viola, $\mathrm{B} 2=$ tegar $45, \mathrm{~B} 3=$ snow waltz, B4 $=$ jayanti, $\mathrm{B} 5=$ giga, $\mathrm{B} 6=$ snow white, $\mathrm{B} 7=$ diamond, $\mathrm{B} 8=$ orient, $\mathrm{B} 9=$ roo so $45, \mathrm{~B} 10=$ forum, $\mathrm{B} 11=$ bima, $\mathrm{B} 12=\mathrm{F} 1$ hybrid, $\mathrm{B} 13=$ arjuna. Pada pengujian benih di Laboratorium dengan metode Uji Kertas Digulung didirikan dalam Plastik (UKDdP) terdiri dari 1 gulungan dengan 50 butir benih.

\section{HASIL DAN PEMBAHASAN}

\section{Daya Berkecambah}

Daya berkecambah merupakan tolok ukur viabilitas benih yang paling banyak digunakan dalam pengujian mutu benih. Menurut Ilyas (2012), viabilitas benih merupakan daya hidup benih, aktif secara metabolisme, dan memiliki enzim yang dapat mengatalisis reaksi metabolisme yang diperlukan untuk perkecambahan dan pertumbuhan kecambah. Berikut hasil analisis ragam uji DMRT menunjukkan bahwa terdapat interaksi antara perlakuan suhu dan beberapa varietas terhadap parameter daya berkecambah dan hasil analisa data percobaan yang diuji lanjut dengan menggunakan DMRT taraf signifikan 5\% analisis statistik. 
Tabel 1. Tabel Anova Daya Berkecambah

\begin{tabular}{lccccr}
\hline $\begin{array}{l}\text { Sumber } \\
\text { Keragaman }\end{array}$ & $\begin{array}{c}\text { Derajat } \\
\text { bebas } \\
(\mathrm{DB})\end{array}$ & $\begin{array}{c}\text { Jumlah } \\
\text { kuadrat } \\
(\mathrm{JK})\end{array}$ & $\begin{array}{c}\text { Kuadrat } \\
\text { tengah } \\
(\mathrm{KT})\end{array}$ & F Hitung & F Tabel \\
\hline $\mathrm{P}$ & 2 & 1440,31 & 720,15 & $18,43^{*}$ & 3,24 \\
$\mathrm{~B}$ & 12 & 16578,46 & 1381,54 & $35,35^{*}$ & 2,01 \\
$\mathrm{P} * \mathrm{~B}$ & 24 & 3315,69 & 138,15 & $3,54^{*}$ & 1,80 \\
Galat & 39 & 1524,00 & 39,08 & & \\
Total & 77 & & & & \\
\hline \multicolumn{5}{l}{ Koefisien Keragaman $(\mathrm{KK}): 10,18 \%$}
\end{tabular}

Tabel 2. Interaksi Antara Suhu dan Beberapa Genotipe Terhadap Daya Berkecambah

\begin{tabular}{cccc}
\hline Suhu & P0 & P1 & P2 \\
Genotipe & Tanpa AC & Ber-AC & Kulkas \\
\hline B1 & $56 \mathrm{a}$ & $47 \mathrm{~b}$ & $40 \mathrm{c}$ \\
(Viola) & $\mathrm{G}$ & $\mathrm{H}$ & $\mathrm{F}$ \\
B2 & $60 \mathrm{c}$ & $78 \mathrm{a}$ & $65 \mathrm{~b}$ \\
(Tegar 45) & $\mathrm{F}$ & $\mathrm{D}$ & $\mathrm{C}$ \\
B3 & $72 \mathrm{~b}$ & $79 \mathrm{a}$ & $66 \mathrm{c}$ \\
(Snow Waltz) & $\mathrm{C}$ & $\mathrm{D}$ & $\mathrm{C}$ \\
B4 & $61 \mathrm{a}$ & $58 \mathrm{~b}$ & $41 \mathrm{c}$ \\
(Jayanti) & $\mathrm{E}$ & $\mathrm{F}$ & $\mathrm{F}$ \\
B5 & $72 \mathrm{~b}$ & $80 \mathrm{a}$ & $66 \mathrm{c}$ \\
(Giga) & $\mathrm{C}$ & $\mathrm{C}$ & $\mathrm{C}$ \\
b6 & $70 \mathrm{~b}$ & $77 \mathrm{a}$ & $36 \mathrm{c}$ \\
(Snow White) & $\mathrm{C}$ & $\mathrm{D}$ & $\mathrm{G}$ \\
B7 & $56 \mathrm{a}$ & $51 \mathrm{~b}$ & $50 \mathrm{~b}$ \\
(Diamond) & $\mathrm{G}$ & $\mathrm{G}$ & $\mathrm{E}$ \\
B8 & $31 \mathrm{a}$ & $30 \mathrm{a}$ & $28 \mathrm{~b}$ \\
(Orient) & $\mathrm{H}$ & $\mathrm{J}$ & $\mathrm{H}$ \\
B9 & $92 \mathrm{a}$ & $86 \mathrm{~b}$ & $86 \mathrm{~b}$ \\
(Roo So 45) & $\mathrm{A}$ & $\mathrm{B}$ & $\mathrm{A}$ \\
B10 & $66 \mathrm{~b}$ & $69 \mathrm{a}$ & $54 \mathrm{c}$ \\
(Forum) & $\mathrm{D}$ & $\mathrm{E}$ & $\mathrm{D}$ \\
B11 & $80 \mathrm{~b}$ & $89 \mathrm{a}$ & $71 \mathrm{c}$ \\
(Bima) & $\mathrm{B}$ & $\mathrm{A}$ & $\mathrm{B}$ \\
B12 & $64 \mathrm{a}$ & $49 \mathrm{~b}$ & $51 \mathrm{~b}$ \\
(F1 Hybrid 50 Days) & $\mathrm{D}$ & $\mathrm{H}$ & $\mathrm{E}$ \\
B13 & $58 \mathrm{~b}$ & $44 \mathrm{c}$ & $65 \mathrm{a}$ \\
(Arjuna) & $\mathrm{G}$ & $\mathrm{I}$ & $\mathrm{C}$ \\
\hline Sumber: & & &
\end{tabular}

Sumber: Data Primer Diolah (2020)

Ket. Nilai rata-rata yang diikuti dengan huruf yang sama pada setiap kolom dengan huruf kecil (vertikal) dan setiap baris huruf besar (horizontal) menunjukkan berbeda nyata menurut DMRT pada taraf $5 \%$. 
Hasil persentase daya berkecambah yang memberikan hasil terbaik yaitu genotipe Roo So 45 yang disimpan dalam suhu tanpa AC (p0b9) yaitu 92\%, sedangkan yang memberikan hasil terburuk yaitu genotipe Orient yang disimpan dalam suhu kulkas (p2b8) yaitu 28\%. Hal tersebut diduga suhu ruang tanpa AC pada saat penyimpanan tidak terlalu tinggi seperti seharusnya yang bisa mencapai $35^{\circ} \mathrm{C}$, yang dilihat dari pengamatan suhu harian. Selain itu saat penyimpanan berlangsung kondisi musim pada tempat penyimpanan yaitu musim hujan, dimana saat musim hujan suhu mengalami penurunan dan kelembaban mengalami kenaikan dibandingkan saat musim kemarau. Jika kondisi iklim mengalami penurunan suhu maka kondisi suhu yang berada pada lingkungan tersebut juga akan mengalami penurunan. Selain itu keberadaan sifat dari bangunan tempat penyimpanan akan mempengaruhi kondisi iklim mikro setempat, seperti suhu dan kelembaban. Sifat dari bangunan berbeda-beda kemampuan penyerapan, memantulkan radiasi matahari dan menyerap suhu udara (Nawawir, 2001).

Pengaruh interaksi terjadi antara suhu dengan beberapa genotipe di duga disebabkan suhu memiliki peranan penting dalam proses perkecambahan yang mempengaruhi reaksi kimia dalam proses perkecambahan. Reaksi kimia yang di maksud yaitu mampu mengaktifkan kerja enzim seperti amilase, lipase dan proteinase dalam proses perkecambahan (Rusmin, et.al., 2014).

Setiap genotipe memiliki suhu optimum dan suhu kardinal berbeda-beda yang mempengaruhi proses hidrolis, imbibisi dan proses lainnya, hal tersebut membuat respon suhu terhadap genotipe berubah saat benih dikecambahkan. Pernyataan tersebut di dukung oleh Gairola, et. al., (2011) yang menyatakan respon suhu pada perkecambahan berbeda-beda tergantung pada genotipe, spesies benih. Kemungkinan genotipe Orient berada pada suhu yang tidak optimum dan membuat daya berkecambah menjadi buruk $\left(25^{\circ} \mathrm{C}-30^{\circ} \mathrm{C}\right.$ suhu optimum).

\section{Keserempakan Tumbuh}

Keserempakan tumbuh yaitu salah satu uji vigor yang menguji kekuatan lot benih berkecambah secara serempak dan berapa persen benih mampu berkecambah secara normal. Berikut hasil analisis ragam uji DMRT menunjukkan bahwa terdapat interaksi antara perlakuan suhu dan beberapa varietas terhadap parameter keserempakan tumbuh dan hasil analisa data percobaan yang diuji lanjut dengan menggunakan DMRT taraf signifikan 5\% analisis statistik.

Tabel 3. Tabel Anova Keserempakan Tumbuh

\begin{tabular}{cccccc}
\hline $\begin{array}{c}\text { Sumber } \\
\text { Keragaman }\end{array}$ & $\begin{array}{c}\text { Derajat } \\
\text { bebas } \\
(\mathrm{DB})\end{array}$ & $\begin{array}{c}\text { Jumlah } \\
\text { kuadrat } \\
(\mathrm{JK})\end{array}$ & $\begin{array}{c}\text { Kuadrat } \\
\text { tengah } \\
(\mathrm{KT})\end{array}$ & $\begin{array}{c}\mathrm{F} \\
\text { Hitung }\end{array}$ & F Tabel \\
\hline $\mathrm{P}$ & 2 & 1428,10 & 714,05 & $18,49^{*}$ & 3,24 \\
$\mathrm{~B}$ & 12 & 16705,95 & 1392,16 & $36,05^{*}$ & 2,01 \\
PxB & 24 & 3323,90 & 138,50 & $3,59^{*}$ & 1,80 \\
Galat & 39 & 1506,00 & 38,62 & & \\
Total & 77 & & & & \\
\hline
\end{tabular}

Koefisien Keragaman (KK): 10,13\% 
Tabel 4. Interaksi Antara Suhu dan Beberapa Genotipe Terhadap Keserempakan Tumbuh

\begin{tabular}{|c|c|c|c|}
\hline $\mathrm{C}_{\text {Genotipe }}^{\text {Suhu }}$ & $\begin{array}{c}\text { P0 } \\
\text { Tanpa AC }\end{array}$ & $\begin{array}{c}\text { P1 } \\
\text { Ber-AC }\end{array}$ & $\begin{array}{c}\text { P2 } \\
\text { Kulkas }\end{array}$ \\
\hline B1 & $56 \mathrm{a}$ & $47 \mathrm{~b}$ & $40 \mathrm{c}$ \\
\hline (Viola) & $\mathrm{G}$ & $\mathrm{H}$ & $\mathrm{F}$ \\
\hline B2 & $60 \mathrm{c}$ & $78 \mathrm{a}$ & $65 \mathrm{~b}$ \\
\hline (Tegar 45) & $\mathrm{F}$ & $\mathrm{D}$ & $\mathrm{C}$ \\
\hline B3 & $72 \mathrm{~b}$ & $79 a$ & $66 \mathrm{c}$ \\
\hline (Snow Waltz) & $\mathrm{C}$ & $\mathrm{D}$ & $\mathrm{C}$ \\
\hline B4 & $61 \mathrm{a}$ & $58 \mathrm{~b}$ & $41 \mathrm{c}$ \\
\hline (Jayanti) & $\mathrm{E}$ & $\mathrm{F}$ & $\mathrm{F}$ \\
\hline B5 & $72 \mathrm{~b}$ & $80 \mathrm{a}$ & $66 \mathrm{c}$ \\
\hline (Giga) & $\mathrm{C}$ & $\mathrm{C}$ & $\mathrm{C}$ \\
\hline B6 & $70 \mathrm{~b}$ & $77 \mathrm{a}$ & $36 \mathrm{c}$ \\
\hline (Snow White) & $\mathrm{C}$ & $\mathrm{D}$ & $\mathrm{G}$ \\
\hline B7 & $56 a$ & $51 \mathrm{~b}$ & $50 \mathrm{~b}$ \\
\hline (Diamond) & $\mathrm{G}$ & G & $\mathrm{E}$ \\
\hline B8 & $30 \mathrm{a}$ & $30 \mathrm{a}$ & $28 \mathrm{a}$ \\
\hline (Orient) & $\mathrm{H}$ & $\mathrm{J}$ & $\mathrm{H}$ \\
\hline B9 & $92 \mathrm{a}$ & $86 b$ & $86 \mathrm{~b}$ \\
\hline (Roo So 45) & A & B & A \\
\hline B10 & $66 \mathrm{~b}$ & $69 \mathrm{a}$ & $54 \mathrm{c}$ \\
\hline (Forum) & $\mathrm{D}$ & $\mathrm{E}$ & $\mathrm{D}$ \\
\hline B11 & $80 \mathrm{~b}$ & $89 \mathrm{a}$ & $71 \mathrm{c}$ \\
\hline (Bima) & B & A & B \\
\hline B12 & $64 \mathrm{a}$ & $49 \mathrm{~b}$ & $51 \mathrm{~b}$ \\
\hline (F1 Hybrid 50 Days) & $\mathrm{D}$ & $\mathrm{H}$ & E \\
\hline B13 & $58 \mathrm{~b}$ & $44 \mathrm{c}$ & $65 \mathrm{a}$ \\
\hline (Arjuna) & G & I & $\mathrm{C}$ \\
\hline
\end{tabular}

Sumber: Data Primer Diolah (2020)

Ket. Nilai rata-rata yang diikuti dengan huruf yang sama pada setiap kolom dengan huruf kecil (vertikal) dan setiap baris huruf besar (horizontal) menunjukkan berbeda nyata menurut DMRT pada taraf $5 \%$.

Hasil persentase daya berkecambah yang memberikan hasil terbaik yaitu genotipe Roo So 45 yang disimpan dalam suhu tanpa AC (p0b9) yaitu 92\%, sedangkan yang memberikan hasil terburuk yaitu genotipe Orient yang disimpan dalam suhu kulkas (p2b8) yaitu 28\%. Hal tersebut diduga varietas Roo So 45 cocok ditanam pada segala musim, dapat ditanam pada ketinggian 50-1500 mdpl, dapat disimpan dalam jangka waktu yang lama dan mampu disimpan pada suhu yang sedang tidak terlalu tinggi, yang tertera pada kemasan.

Menurut Lesilolo, et.al. (2013) persentase keserempakan tumbuh suatu genotipe benih berkisar 40-70\%, jika lebih besar dari 70\% maka indikasi vigor genotipe benih tersebut sangat tinggi, namun bila kurang dari $40 \%$ maka sebaliknya vigor genotipe benih tersebut kurang tinggi. Maka kaitannya dengan suhu diduga karena proses respirasi pada setiap perlakuan genotipe berbeda-beda, 
sehingga kecambah normal yang dihasilkan dapat menurun maupun meningkat tergantung dari proses respirasi tersebut berjalan.

Pada suhu yang terlalu rendah ada 2 kemungkinan yaitu semakin rendah suhu penyimpanan maka semakin lambat laju deteriorasi sehingga benih dapat disimpan lebih lama dan yang kedua yaitu jika semakin rendah suhu penyimpanan maka enzim akan mengalami pembekuan (koagulasi) sehingga sifat katalik dan aktifitas benih menurun, akan tetapi enzim sangat berkaitan dengan proses-proses seluler seperti respirasi dan proses metabolisme akan berjalan lambat atau kemungkinan tidak dapat terjadi (Susanti, 2011). Hal tersebut akan menyebabkan benih yang dikecambahkan tidak dapat berkecambah dengan cepat atau membutuhkan waktu.

Benih membutuhkan waktu untuk dapat berkecambah karena selama penyimpanan berlangsung membuat struktuk kulit benih menjadi lebih keras dan pada saat benih akan di tanam, benih hanya mengalamai cracking (peretakan pada kulit benih). Peretakan merupakan berkembangnya proses pematahan dormasi dan membantu proses perkecambahan pada benih, karena air akan menyerap kedalam benih. Tetapi jika kulit benih yang terlalu keras akibat suhu yang terlalu rendah maka penyerapan air kedalam benih akan terhambat dan menyebabkan benih butuh waktu lebih lama untuk berkecambah (Puspaningrum, et.al., 2013).

\section{Indeks Vigor}

Indeks vigor digunakan untuk mengetahui kemampuan tumbuh benih. Vigor benih menjadi acuan utama menentukan mutu suatu benih. Benih yang memiliki vigor tinggi dapat menghasilkan tanaman yang tegar meski kondisi lapangan atau lingkungan tumbuh tidak optimum (Sadjad, et al., 1999)

Berikut hasil analisis ragam uji DMRT menunjukkan bahwa terdapat interaksi antara perlakuan suhu dan beberapa varietas terhadap parameter keserempakan tumbuh dan hasil analisa data percobaan yang diuji lanjut dengan menggunakan DMRT taraf signifikan 5\% analisis statistik.

Hasil persentase indeks vigor yang memberikan hasil terbaik yaitu genotipe Roo So 45 yang disimpan dalam suhu tanpa AC (p0b9) yaitu 87\%, sedangkan yang memberikan hasil terburuk yaitu genotipe Orient yang disimpan dalam suhu kulkas (p2b8) yaitu 25\%.

Tabel 5. Tabel Anova Indeks Vigor

\begin{tabular}{cccccc}
\hline $\begin{array}{c}\text { Sumber } \\
\text { Keragaman }\end{array}$ & $\begin{array}{c}\text { Derajat } \\
\text { bebas } \\
(\mathrm{DB})\end{array}$ & $\begin{array}{c}\text { Jumlah } \\
\text { kuadrat } \\
(\mathrm{JK})\end{array}$ & $\begin{array}{c}\text { Kuadrat } \\
\text { tengah } \\
(\mathrm{KT})\end{array}$ & F-hitung & F tabel \\
\hline P & 2 & 1112,10 & 556,05 & $15,42^{*}$ & 3,24 \\
B & 12 & 16674,15 & 1389,51 & $38,54^{*}$ & 2,01 \\
PxB & 24 & 2929,23 & 122,05 & $3,39^{*}$ & 1,80 \\
Galat & 39 & 1406,00 & 36,05 & & \\
Total & 77 & & & & \\
\hline
\end{tabular}

Koefisien Keragaman (KK): 10,32\% 
Tabel 6. Interaksi Antara Suhu dan Beberapa Genotipe Terhadap Indeks Vigor

\begin{tabular}{|c|c|c|c|}
\hline $\mathrm{C}_{\text {Genotipe }}^{\text {Suhu }}$ & $\begin{array}{c}\text { P0 } \\
\text { Tanpa AC }\end{array}$ & $\begin{array}{c}\text { P1 } \\
\text { Ber-AC }\end{array}$ & $\begin{array}{c}\text { P2 } \\
\text { Kulkas }\end{array}$ \\
\hline B1 & $52 \mathrm{a}$ & $42 \mathrm{~b}$ & $37 \mathrm{c}$ \\
\hline (Viola) & $\mathrm{H}$ & I & $\mathrm{H}$ \\
\hline B2 & $59 \mathrm{c}$ & $76 \mathrm{a}$ & $64 \mathrm{~b}$ \\
\hline (Tegar 45) & $\mathrm{F}$ & $\mathrm{C}$ & $\mathrm{C}$ \\
\hline B3 & $66 \mathrm{~b}$ & $76 a$ & $62 \mathrm{c}$ \\
\hline (Snow Waltz) & $\mathrm{D}$ & $\mathrm{C}$ & $\mathrm{D}$ \\
\hline B4 & $59 \mathrm{a}$ & $56 \mathrm{~b}$ & $38 \mathrm{c}$ \\
\hline (Jayanti) & $\mathrm{F}$ & $\mathrm{F}$ & $\mathrm{G}$ \\
\hline $\mathrm{B} 5$ & $69 \mathrm{~b}$ & $75 \mathrm{a}$ & $63 \mathrm{c}$ \\
\hline (Giga) & $\mathrm{C}$ & $\mathrm{D}$ & $\mathrm{D}$ \\
\hline B6 & $66 \mathrm{~b}$ & $74 \mathrm{a}$ & $36 \mathrm{c}$ \\
\hline (Snow White) & $\mathrm{D}$ & $\mathrm{D}$ & $\mathrm{H}$ \\
\hline B7 & $52 \mathrm{a}$ & $48 \mathrm{~b}$ & $48 \mathrm{~b}$ \\
\hline (Diamond) & $\mathrm{H}$ & $\mathrm{G}$ & $\mathrm{F}$ \\
\hline B8 & $27 \mathrm{a}$ & $26 \mathrm{~b}$ & $25 \mathrm{~b}$ \\
\hline (Orient) & I & $\mathrm{J}$ & I \\
\hline B9 & $87 \mathrm{a}$ & $84 \mathrm{~b}$ & $85 \mathrm{~b}$ \\
\hline (Roo So 45) & A & $\mathrm{A}$ & A \\
\hline B10 & $61 \mathrm{~b}$ & $66 \mathrm{a}$ & $51 \mathrm{c}$ \\
\hline (Forum) & $\mathrm{E}$ & $\mathrm{E}$ & $\mathrm{E}$ \\
\hline B11 & $77 \mathrm{~b}$ & $82 \mathrm{a}$ & $68 \mathrm{c}$ \\
\hline (Bima) & $\mathrm{B}$ & B & $\mathrm{B}$ \\
\hline B12 & $59 a$ & $46 \mathrm{c}$ & $48 \mathrm{~b}$ \\
\hline (F1 Hybrid 50 Days) & $\mathrm{F}$ & $\mathrm{H}$ & $\mathrm{F}$ \\
\hline B13 & $54 \mathrm{~b}$ & $43 \mathrm{c}$ & $62 \mathrm{a}$ \\
\hline (Arjuna) & $\mathrm{G}$ & I & D \\
\hline
\end{tabular}

Sumber: Data Primer Diolah (2020)

Ket. Nilai rata-rata yang diikuti dengan huruf yang sama pada setiap kolom dengan huruf kecil (vertikal) dan setiap baris huruf besar (horizontal) menunjukkan berbeda nyata menurut DMRT pada taraf 5\%.

Hal tersebut diduga benih yang memiliki persentase daya berkecambah maka nilai indeks vigornya akan tinggi pula, sebaliknya jika benih dengan persentase daya berkecambah rendah maka nilai indeks vigornya rendah juga (Sunyoto dan Octriana, 2013).

Terdapat interaksi antara perlakuan suhu dan varietas pada pengamatan persentase indeks vigor, walau hasil terbaik pada setiap perlakuan berbeda-beda. Hal tersebut diduga kemampuan masing-masing varietas berbeda-beda untuk tumbuh normal yang dilihat dari kondisi varietas benih tersebut (Kolo dn Tefa, 2016).

\section{KESIMPULAN DAN SARAN}

Berdasarkan hasil penelitian yang telah di lakukan maka dapat disimpulkan bahwa terdapat interaksi pada penelitian terhadap suhu dan beberapa genotipe terhadap viabilitas dan vigor benih kubis bunga (Brassica oleracea var. botrytis 
L.) pada dataran rendah pada parameter daya berkecambah, keserempakan tumbuh dan indeks vigor.Perlakuan Genotipe yang memberikan hasil terbaik yaitu Roo So 45 pada setiap parameter, sementara perlakuan suhu yang memberikan hasil terbaik yaitu suhu ruang tanpa AC dan suhu ruang ber-AC.

Berdasarkan hasil penelitian yang telah dilakukan, disarankan untuk menguji lebih lanjut genotipe-genotipe benih kubis bunga (Brassica oleracea var. botrytis L.) untuk mengetahui karakteristik pada setiap genotipe.

\section{DAFTAR PUSTAKA}

Gairola, K.C., Nautiyal, A.R., and Dwivedi, A.K. 2011. Effect Of Temperatures And Germination Media On Seed Germination Of Jatropha Curcas Linn. Journal of Forest and Environmental Science, 2 (2): 66-71

Hutabarat, T.G., Sumaryo, G.S., dan Suriaty, S. 2013. Analisis Loyalitas Petani Terhadap Benih Padi Unggul Di Kecamatan Seputih Raman Kabupaten Lampung Tengah. Jurnal IIA, 1 (3): 254-263.

Ilyas, S. 2012. Ilmu dan Teknologi Benih, Teori dan Hasil-hasil Penelitian. Bogor: IPB.

Kolo, E., dan Tefa, A. 2016. Pengaruh Kondisi Simpan Terhadap Viabilitas Dan Vigor Benih Tomat (Lycopersicum esculentum, Mill). Jurnal Pertanian Konservasi Lahan Kering, 1 (3): 112-115.

Lesilolo, M.K., Riry, J., dan Matatula, E.A. 2013. Pengujian Viabilitas dan Vigor Benih Beberapa Jenis Tanaman yang Beredar di Pasaran Kota Ambon. Jurnal Agrologia, 2 (1): 1-9.

Marliah, A., Nurhayati dan Riana, R. 2013. Pengaruh Varietas Dan Konsentrasi Pupuk Majemuk Terhadap Pertumbuhan Dan Hasil Tanaman Kubis Bunga (Brassica oleracea L.). Jurnal Floratek, 8 (2): 118-126.

Mufid, K. 2017. Pengaruh Osmoconditioning Dengan Larutan PEG (Polyethylene Glycol) 6000 Terhadap Viabilitas Benih Bunga Matahari (Helianthus annus L.). Skripsi. Universitas Islam Negeri Maulana Malik Ibrahim.

Nawawir, G., 2001. Modul Dasar Bidang Keahlian Kode Modul SMKP1D0304DBK Pengendalian Iklim Mikro. Bandung: Departemen Pendidikan Nasional Proyek Pengembangan Sistem Dan Standar Pengelolaan SMK Direktorat Pendidikan Menengah Kejuruan Jakarta.

Nurhayani, F.O., dan Wulandari, A.S. 2019. Pengaruh Periode dan Media Simpan terhadap Viabilitas Benih Kenanga (Cananga odorata (Lam.) Hook.f. \& Thomson forma genuina). Jurnal Sylva Lestari, 7 (3): 277-288. 
Oktaviana, Z., Ashari, S., dan Purnamaningsih, S.L. 2016. Pengaruh Perbedaan Umur Masak Benih Terhadap Hasil Panen Tiga Varietas Lokal Mentimun (Cucumis sativus L.). Jurnal Produksi Tanaman, 4 (3): 218-223.

Purwanti, M.D. 2015. Efektifitas Kemasan dan Suhu Ruang Simpan terhadap Daya Simpan Benih Kedelai (Glycine max (L.) Meirril). Planta Tropika Journal of Agro Science, 3 (1) :1-7.

Puspaningrum, C., Muin, A., dan Wulandari, S.R. 2013. Pengaruh Beberapa Perlakuan Terhadap Masa Dormasi Biji Belian (Eusideroxylon zwageri T.et.B). Jurnal Hutan Lestari, 1 (2): 61-68.

Rusmin, R., Astami, E.W., and Hartadi, B. 2014. The Impact Of Surplus Free Cash Flow And Audit Quality On Earnings Management The Case Of Growth Triangle Countries. European Journal of Marketing, 22 (2): 118-133.

Sadjad, S. 1993. Dari Benih Kepada Benih. Jakarta: Grasindo.

Saputri, C.W.E., Pudja, I.A.R.P., dan Kencana, P.K.D. 2020. Pengaruh Perlakuan Waktu Dan Suhu Penyimpanan Dingin Terhadap Mutu Kubis Bunga (Brassica Oleracea L. Var. Botrytis). Jurnal Beta, 8 (1): 138-144.

Sari, W., dan Faisal, M.F. 2017. Pengaruh Media Penyimpanan Benih Terhadap Viabilitas Dan Vigor Benih Padi Pandanwangi. Jurnal Agroscience, 7 (2): 300-310.

Subantoro, R., dan Prabowo, R. 2013. Pengkajian Viabilitas Benih Dengan Tetrazolium Test Pada Jagung dan Kedelai, Mediagro, 9 (2) Hal 1-8.

Sugiarto, A., Hanifa, M., dan Sarno. 2018. Pemanasan Global di Sumatera Selatan dan Peningkatan Suhu Udara yang Terjadi; Pemodelan Pengaruhnya Terhadap Transpirasi Lansium domesticum Corr. Skripsi. Universitas Sriwijaya.

Sunyoto, dan Octriana, L. 2013. Kajian Pengaruh Suhu Simpan Dan Metode Pematahan Dormansi Terhadap Viabilitas Benih Pepaya Merah Delima: Laporan Hasil Penelitian. Balai Penelitian Tanaman Buah Tropika. Solok, Sumatera Barat.

Susanti, E.D. 2011. Pengaruh Suhu Dan Lama Penyimpanan Terhadap Viabilitas Benih Tembakau (Nicotiana Tabacum). Skripsi. Universitas Islam Negeri Maulana Malik Ibrahim. 